Cilt: 16 Sayn: $31,128-148$

\title{
TÜBITTAK 4006 Bilim Fuarlarına Fen Projeleriyle Katılan Öğrencilerin Velilerinin Bilim Fuarları Hakkındaki Görüşleri*
}

\author{
Pinar Ural Keleş ${ }^{* *}$, Hamza Soyuçok ${ }^{* * *}$ \\ Makale Geliş Tarihi: 01/05/2020 \\ Makale Kabul Tarihi: 28/09/2020 \\ DOI: $10.35675 /$ befdergi. 730540
}

$\ddot{O} z$

Bu araştırmanın amacı; TÜBITAK 4006 bilim fuarlarına fen projeleri ile katılan ögrencilerin velilerinin bilim fuarları hakkındaki görüşlerini belirlemektir. Çalışmada özel durum yöntemi kullanılmıştır. Araştırmanın örneklemini TÜBITAK 4006 Bilim Fuarlarına fen projeleri katılan 30 ögrencinin velisi oluşturmaktadır. Araştırmanın verileri 7 sorudan oluşan bir anket formu ile toplanmıştır. Elde edilen velilerin analizinde içerik analizinden yararlanılmıştır. Çalışmada araştırmaya katılan velilerinin \%66,6'sının öğrencilerinin bilim fuarına fen projeleriyle katılmasını istediği, \% 73,3'ünün proje hazırlama sürecinde öğrencilerine yardımcı olduğu belirlenmesine rağmen önemli bir bölümünün bu etkinlikleri izlemeye gitmediği saptanmıştır. Çalışmada ayrıca bazı velilerinin Bilim Fuarları için ögrencilerin hazırlaması gereken projeleri üstlendiğine işaret eden bulgulara rastlanırken bazı velilerin de öğrencilerinin Bilim Fuarlarına tekrar katılmasın istemediği belirlenmiştir.

Anahtar Kelimeler: 4006 TÜBİTAK bilim fuarları, fen projeleri, ögrenci velilerinin bilim fuarları hakkındaki görüşleri

\section{Opinions of Parents of Students Attending TÜBITTAK 4006 Science Fairs with Science Projects about Science Fairs}

\section{Abstract}

The purpose of this study is to determine the views of parents of students who participated in TÜBITAK 4006 science fair on science fairs. Case study method was used in the study. The sample of the study consists of the parents of 30 students who participated in TÜBITAK 4006 Science Fairs with their science projects. The data of the study was collected by a questionnaire consisting of 7 questions. It was determined that although $66.6 \%$ of the parents who participated in the study wanted their children to participate in science fair with science projects and $73.3 \%$ of them helped their students in the project preparation process, majority of them didn't go to see their children in these science fairs. In the study, results were found indicating that some of the parents undertook the projects that students should prepare for

\footnotetext{
* Bu çalışma Doç. Dr. Pınar URAL KELEŞ danışmanlığında Hamza SOYUÇOK tarafından yapılan yüksek lisans tezinin bir bölümüdür.

** Ağrı İbrahim Çeçen Üniversitesi, Eğitim Fakültesi, Temel Eğitim Bölümü, Sınıf Eğitimi Anabilim Dalı, Ağrı, Türkiye, pukeles@ yahoo.com, ORCID: 0000-0001-6325-0152 (D)

**** Milli Eğitim Bakanlığı, Denizli/Türkiye, soyucokhamza@hotmail.com, ORCID: 00000003-0386-3162
}

Kaynak Gösterme: Ural Keleş, P., \& Soyuçok, H. (2021). Tübitak 4006 bilim fuarlarına fen projeleriyle katılan öğrencilerin velilerinin bilim fuarları hakkındaki görüşleri. Bayburt Eğitim Fakültesi Dergisi, 16(31), 128-148. https://doi.org/10.35675/befdergi.730540. 
Science Fairs, while some parents stated that they did not want their students to participate in these activities again.

Keywords: 4006 TÜBITAK science fairs, science projects, view of students' parents on science fairs

\section{Giriş}

Günümüzde eğitim ortamlarında öğreticinin bilgiye ulaşma yollarını gösteren bir rehber olarak görüldüğü, öğrencilerin merkeze alarak sorumluluğun onlara bırakıldığg1, onların üst düzey düşünme becerilerine odaklanmasına olanak sağlandığ1 kısacası bilgiye ulaşma becerilerini öğrencilere kazandırmayı amaçlayan yaklaşımların kullanılması önerilmektedir (Millî Eğitim Bakanlığı [MEB], 2018; Demiral, 2015). Çağdaş öğretim yaklaşımları olarak adlandırılan bu yaklaşıma ait yöntemlerden biride "Proje tabanlı öğrenme" yöntemidir (Demiral, 2015).

Proje tabanlı öğrenme yaklaşımı incelendiğinde; öğretmenin yönlendirici rolünde olduğu, öğrencilerin öğrenme sorumluluklarını sahiplendiği ve bireysel ya da grup halinde bir konunun iş birliği içerisinde ilgi ve yeteneklere göre araştırıldığ bilişsel becerilerin edinildiği ve ürün veya sunumla sonuçlanan bir yöntem olduğu görülmektedir (Dilşeker, 2008). Bu öğrenme sürecinde öğrencilerin meraklarını gidermek adına sorular sorarak bilginin peşine düştüğü ve çeşitli kaynaklardan bilgiler toplayarak, bilgiyi sentezler, analiz eder ve yeni bilgiler ürettikleri belirtilmektedir (Solomon, 2003). Konu ile ilgili literatürde proje tabanlı öğrenme yönteminin öğrenme ortamlarında kullanılmasının; öğrencilerin akademik başarılarını artırdığ (Doğay, 2010; Demiray, 2013; Kaşarc1, 2013; Yılmaz, 2015; Özünal, 2016), bilimsel süreç becerilerini geliştirdiği (Bahar vd., 2014; Kavacık, Kılınç \& Kavacık, 2015) belirtilmektedir. Ayrıca bu yöntemin öğrencilerin yaratıcı, eleştirel, sosyal düşünme becerileri ile iletişim becerileri geliştirdiği yanı sıra sorunlarla baş edebilme becerisi kazanmalarına önemli katkılar sağladığı rapor edilmektedir (Bahar vd., 2014; Bolat vd., 2014; Kavacık, Kılınç \& Kavacık, 2015; Yılmaz, 2015). Bu noktalar öğrenme ortamlarında proje tabanlı öğrenme yaklaşımlarının kullanılmasının önemi ortaya çıkmaktadır.

Öğrencilerin aktif bir şekilde proje çalışmalarında yer almalarını sağlayan programlardan biride "Türkiye Bilimsel ve Teknolojik Araştırma Kurumu (TÜBİTAK), 4006 Bilim Fuarları" dır. TÜBİTAK Bilim Fuarları; ortaögretimde bilim kültürünün geliştirilmesine yönelik olarak MEB'e bağll devlet okullarl, Mesleki Ĕ̆itim Merkezleri ve Bilsem'lerde düzenlenen, TÜBİTAK tarafindan uygun görülen alt projelerin sergilendiği programlar" olarak ifade edilmektedir (TÜBİTAK, 2018a, s4). $\mathrm{Bu}$ bilimsel faaliyetlerin amac1; "5-12. sını ögrencilerinin; kendi ilgileri doğrultusunda belirledikleri konular üzerine araştırma yapabilecekleri, araştırmalarının sonuçlarını sergileyebilecekleri, eğlenerek öğrenebilecekleri bir ortam oluşturulmak” olarak belirlenmiştir (TÜBİTAK, 2018d, s2). Bilim Fuarları sayesinde, öğrencilerin bireysel ilgileri doğrultusunda hazırladıkları alt projelerle, 
onların bilimsel araştırma süreçlerini yaşayarak öğrenebilecekleri bununla birlikte eleştirel düşünme, zaman yönetimi, problem çözme, özgüven ve liderlik vasıflarının da gelişebileceği belirtilmektedir (TÜBİTAK, 2018a). Bilim fuarları, başvuru yapan okulların kendi bünyesinde gerçekleştirildiğinden, yarışma baskısını ortadan kaldırmakta, bu etkinliklere katılma imkânı bulamayan uzak köy okullarına da başvurabilme şansı sunduğundan fırsat eşitliğinin sağlanmasına yardımcı olunmaktadır (Avcı \& Su Özenir, 2018). Bu fuarlarının en önemli avantajlarından biri de organizasyonun yapılabilmesi için TÜBİTAK'tan her okul için maddi destek alınmasıdır. Bu kapsamda sağlanan destek, bilim fuarı yürütücüsünün yetkisinde, gerçekleştirilen bilim fuarları için harcanmaktadır. Tübitak, "4006 Bilim Fuarları" kapsamında, 2013 yılında 1000 adet, 2014 yılında 1000 adet ve 2015 yılında yaklaşık 3400 adet ortaokul ve liseye destek vermiştir. 2018-2019 çağrı döneminde ise 4006 Tübitak Bilim Fuarları Destekleme Programına yapılan 13.541 proje başvurusunun değerlendirmeye alındığ 1 belirtilmektedir (TÜBİTAK, 2018b). TÜBİTAK, 4006 Bilim Fuarları kapsamında başvuru sayısının ve TÜBİTAK tarafindan destek verilen proje sayısının yıldan yıla artması bu etkinliklerin önemini açıkça ortaya koymaktadır.

Öte yandan güncellenen öğretim programlarında araştıran ve sorgulayan öğrenci modelinin ön plana çıktığı ve öğrencileri eskisine oranla daha fazla materyal kullanmaya, tasarım yapmaya ve soru sormaya teşvik edilmesi gerektiği belirtilmektedir (MEB, 2018; Çepni, Ayvacı \& Bakırc1, 2012). Bu kapsamda güncellenen 2018 Fen Bilimleri dersi öğretim programlarında da TÜBITAK 4006 Bilim Fuarlarına yer verildiği görülmektedir (MEB, 2017). Fen Bilimleri dersi öğretim programında dersin "Bilgi" Öğrenme alanına "Fen ve Mühendislik Uygulamaları" alt öğrenme alanı eklenerek, öğrenme alanları sayısı 4'ten 5'e çıarılmıştır. Fen ve Mühendislik Uygulamaları alt öğrenme alanı; 4, 5, 6, 7 ve 8. sınıflarda eğitim öğretim döneminin son üç haftasına yerleştirilmiş bu sayede proje, sergi, bilim fuarı gibi faaliyetlere zaman ayrılarak okul ortamında hazırlanan materyallerin sergileneceği bilim şenliği uygulamalarının yapılması hedeflenmiştir (MEB, 2017). Okullarda yapılacak bu etkinlikler ile öğrencilerin bilimsel araştırma yapmayı dolayısıyla bilgiye ulaşmak için kullanılan bilimsel adımları öğrenmeleri amaçlanmıştır (Efe \& Aslan Efe, 2018; TÜBİTAK, 2018c).

Diğer taraftan güncellenen Fen Bilimleri dersinde önemli bir yer tutan ve bilim fuarlarının temelini oluşturan Proje Tabanlı Öğrenme sürecinde, roller sadece öğretmen ve öğrenciler tarafından paylaşılmamaktadır. Bu sürecin önemli bir parçasını da öğrenci velileri oluşturmaktadır (Güvey, 2009). Bu durum velilerinin kendilerini bu faaliyetlerinin bir parçası gibi hissetmesi gerekliliğini gündeme getirmektedir. İlgili literatürde öğrenci velisinin eğitim öğretim sürecine katmadan, öğrenciyi çok yönlü yetiştirmenin mümkün olmadığı ve verilen eğitimin amaçlarına ulaşabilmesi için öğrenci velisinin ilgi ve yardımına ihtiyaç duyulduğu belirtilmektedir (Taymaz, 2001). Dolayısıyla Proje Tabanlı Öğrenme sürecinde de kendilerini sorumlu hisseden velilerin çocuklarının; ilgili dersin istenen hedeflerine 
ulaşmasının daha kolay olacağı açıktır (Akbaba Altun 2009; Çepni, Ayvacı \& Bakırcı, 2012; Erdoğan \& Demirkasımoğlu 2010; Yaşar, 2010). Okullarda düzenlenen Bilim fuarlarındaki etkinliklerinin temelini Proje Tabanlı Öğrenme oluşturduğundan, velilerinin bu faaliyetler hakkında neler düşündüğü önemli hale gelmektedir.

İlgili literatür incelendiğinde Bilim fuarları konu alan çalışmaların oldukça sınırlı olduğu görülmektedir. Bunlardan Çavuş, Balçın ve Yılmaz (2018) tarafından 43 ortaokul öğrencisi ile Bilim fuarı etkinliklerinin, ortaokul öğrencilerinin fen becerileri ile problem çözme becerilerine yönelik algılarına etkisini incelemek amacıyla yapılan çalışmada; bilim fuarlarının öğrencilerin fen becerileri ve problem çözme becerileri üzerinde pozitif yönlü etkisinin olduğu saptanmıştır. Mupezeni and Kriek (2018) tarafından yapılan çalışmada kırsal kesimde ve kent merkezinde yaşayan öğrencilerin bilim fuarları deneyimlerini karşılaştırmak amaçlanmıştır. Durum çalışması kullanılarak 11 katılımcı ile gerçekleştirilen çalışma da katılımcıların 6'sı kırsal, 5'i kent merkezinde yaşayan öğrencilerdir. Elde edilen veriler kırsal kesimdeki öğrencilerin ortaya koyduğu çalışmaların kent merkezindeki öğrencilere göre zayıf kalmasına rağmen, bilim fuarlarının hem kırsal hem de kent merkezinde öğrenim gören öğrencilerin problem çözme ve eleştirel düşünme becerilerinin gelişmesinde etkili olduğu rapor edilmiştir.

Bilim fuarları uygulamaları ile ilgili farklı kesimlerin görüşlerini irdeleyen çalışmalara bakıldığında ise bu çalışmaların öğretmen öğrenci görüşlerine odaklandığı görülmektedir. Bu çalışmalardan Avcı ve Su Özenir (2018) tarafından yapılan çalışmada, bilim fuarı süreci, proje yürütücüsü 214 öğretmenin gözünden değerlendirilmiştir. Betimsel olarak yürütülen araştırmada bilim fuarları sürecinin amacına hizmet ettiğini ve okullar için olumlu katkılar sağlayan bir organizasyon olduğu belirtilmiş̧ir. Sontay ve diğerleri (2019) tarafından yapılan çalışmada ise 4006-TÜBİTAK Bilim Fuarlarına katılan 12 sekizinci sını öğrencisinin bilim fuarı hakkındaki görüşlerini incelenmiştir. Çalışmada bilim fuarlarının öğrencilerin fen dersine karşı olumlu tutum ve beceriler kazanmalarına yardımcı olduğu ve fen konularını daha iyi öğrenmelerine ve konuların pekiştirmelerine imkân sağladığı belirlenmiştir. Bozdemir (2018) tarafından yapılan çalışmada ise TÜBİTAK bilim fuarı için yapılan projelerin öğrenci üzerindeki etkililiği değerlendirilmiştir. Bilim fuarı gerçekleştiren okullar arasından seçilen okullarda görev alan 164 danışman ve 18 proje yürütücüsü öğretmenleri ile yürütülen çalışmada proje yürütücüsü öğretmenlerin bu uygulamanın öğrencilerin çevresiyle iletişim kurabilmesine, birçok beceriyi sergileyebilmesine, birlikte hareket edebilmesine, bilimsel düşünebilme özelliğini göstermesine yardımcı olduğu belirlenmiştir. Çalışmaya katılan öğretmenlerin ise projelerin öğretmen odaklı yürütülmesi, danışman öğretmenlerin rehberlik süreciyle ilgili eksikliği, öğrenciye kazandırılan becerilerin nitelik yönünden sıkıntılı olması ve proje hazırlık sürecine ayrılan zamanın yeterli olmaması noktalarını bilim fuarlarının geliştirilmesi gereken alanları olduğunu vurgulamıştır. Balcı (2019) tarafından 60 öğretmen ve 352 öğrenci ile yapılan çalışmada ise TÜBİTAK 4006 Bilim Fuarları Destekleme Programına düzenleyici olarak katılan öğretmenlerin ve 
öğrencilerin bilim fuarları hakkındaki görüşlerinin incelenmesi amaçlanmıştır. Çalışmada öğretmenlerin bilim fuarlarının öğrencileri bilimsel çalışmaya yönlendirmesini, bilim fuarlarının etkili bir aktivite olduğunu ve öğrencilerde bilgi artı̧̧ını sağladığını olumsuz olarak değerlendirirken raporu hazırlamanın zor olmasını, yoğun çalışma gerektirmesini, proje bütçesinin yetersiz olmasını ve bazı okul idarecileri tarafindan fuarların zorunlu tutulmasını olumsuzluk olarak değerlendirdikleri belirlenmiştir. Öğrenciler bilim fuarlarının olumlu yönünü akademik başarıya ve günlük hayatta karşılaşılan problemlerin çözümüne olumlu etki olarak ifade etmişlerdir. İlgili literatürde bilim fuarlarına fen projeleri ile katılan öğrenci velilerinin bu uygulama ile ilgili görüşlerini yansıtan bir çalışmaya ise ulaşılamamıştır.

$\mathrm{Bu}$ noktalar eğitim öğretim faaliyetlerinin paydaşlardan birisi olan velilerin TÜBİTAK 4006 Bilim Fuarları hakkındaki görüşlerini önemli hale getirmektedir. Yukarıda verilen literatür ışığında bu çalışmanın amacı; TÜBİTAK 4006 Bilim Fuarlarına fen projeleri ile katılan öğrencilerin, velilerinin bilim fuarları hakkındaki görüşlerini belirlemek olarak saptanmıştır.

\section{Yöntem}

\section{Araştırma Modeli}

$\mathrm{Bu}$ araştırmada özel durum yönteminden yararlanılmıştır. " $B u$ yöntemin en önemli avantajı araştırmacıya çok özel bir konu ya da durum üzerinde yoğunlaşma firsatı vermesidir" (Çepni, 2012, s. 66). Ayrıca eğitim araştırmalarının doğasına da oldukça uygundur (Cohen vd., 2000). Bu araştırmada TÜBİTAK 4006 Bilim Fuarlarına fen projeleri ile katılan öğrencilerin velilerinin bilim fuarları hakkındaki görüşleri derinlemesine araştırılmak istendiğinden özel durum yönteminin kullanılması tercih edilmiştir.

\section{Çalışma Grubu}

Araştırmanın örneklemini; 2015-2016 eğitim-öğretim yılında Ağrı il merkezindeki ortaokullarda yapılan TÜBİTAK 4006 Bilim Fuarlarına öğrencileri fen projeleri ile katılan ve yapılan bu etkinlikleri izlemeye gelen 30 öğrenci velisi oluşturmaktadır. Literatürde özel durumu ile yürütülen çalışmalarda genellikle amaçlı örneklem yönteminin tercih edildiği bildirilmektedir (Yıldırım \& Şimşek, 2011; Çepni, 2012). $\mathrm{Bu}$ araştırmanın örnekleminin belirlenmesinde de amaçlı örneklem yöntemi içerisinde yer alan ölçüt örneklemeden yararlanılmıştır. Ölçüt örneklemesinde, araştırmanın konusu olan herhangi bir durum, ölçüt olarak belirlenebileceği bildirilmektedir (Grix, 2010). Bu araştırmanın örnekleminin belirlenmesinde TÜBİTAK 4006 Bilim Fuarlarında fen alanındaki projelerle aktif olarak katılan öğrenci velisi olmak ve projeleri izlemeye gelmek ölçüt olarak belirlenmiştir. Bu çalışma; araştırma ve yayın etiği kuralları gereği gerekli izinler alınarak yürütülmüştür (Ağrı İl Milli Eğitim Müdürlüğü, 20/07/2016 tarih ve 34550427/300/7709481 nolu yazı). Araştırmada 
ayrıca öğrenci velilerinin verdikleri cevaplar etik kuralları gereği araştırmacılar tarafından gizli tutulmuş ve kimseyle paylaşılmamıştır.

\section{Veri Toplama Aracı}

$\mathrm{Bu}$ araştırmada veri toplama aracı olarak TÜBİTAK 4006 Bilim Fuarlarına fen projeleri ile katılan öğrencilerin bilim fuarları hakkındaki görüşlerini almak üzere araştırmacılar tarafından geliştirilen bir anket formu kullanılmıştır. Anket; insanların yaşam koşullarını, davranışlarını, inançlarını veya tutumlarını betimlemeye yönelik bir dizi sorudan oluşan bir araştırma materyali olarak tanımlanmaktadır (Thomas, 1998). Çalışmada kullanılacak anket formunun geliştirilmesi sürecinde öncelikle yerli ve yabancı literatür incelenmiştir. Bu aşamada özellikle TÜBİTAK 4006 Bilim Fuarlarının tanıtıldığı (öğrenci, öğretmen, veli, okul müdürleri) kılavuz kitapları incelenerek bilim fuarlarının amaçları ve özellikleri belirlenmeye çalışılmıştır. Çalışmada kullanılan anket formunda yer alan soruların oluşturulmasında TÜBİTAK 4006 Bilim Fuarlarının amaçları ve Fen Bilimleri dersi öğretim programının alt amaçlarından dikkate alınmıştır. Ankette yapılandırılmış, açık uçlu ve evet hayır yönündeki sorulara yer verilmiştir. Ankette yer alan yapılandırılmış soru maddesi, öğrenci velilerinin bilim fuarına fen alanında katılmanın öğrencilere sağlayabileceği katkılara ilişkindir. Sorunun yapılandırılmış bölümündeki seçenekler; TÜBİTAK 4006 Bilim Fuarlarının tanıtıldığı, amaç ve özelliklerinin yer aldığı öğrenci, öğretmen, veli, okul müdürleri kılavuz kitapları incelenerek belirlenmeye çalışılmıştır (TÜBİTAK, 2018a, TÜBİTAK, 2018b, TÜBİTAK, 2018c)

Hazırlanan sorular öncelikle fen eğitimi alanında yüksek lisans yapmakta olan ve aynı zamanda ortaokullarda düzenlenen bilim fuarlarında fen projelerinin danışmanlığını üstlenen 4 Fen Bilgisi öğretmenlerine, alanında uzman öğretim elemanlarına ve dil uzmanına incelettirilmiştir. Gelen dönütler doğrultusunda öğrenci velilerinin fen alanında bilim fuarına katılmasının öğrencilere sağlayabileceği katkılara ilişkin sorunun "Öğrencilerin farklı özelliklerine sağlayabileceği katkılar”" ve "Derslere sağlayabileceği katkılar" olarak iki kısma ayrılarak sorulmasına karar verilmiştir. Ayrıca aynı sorunun birden fazla seçeneğin işaretlenebileceği yapılandırılmış birinci bölüm dışında velilerin soruya ilişkin kendi cevaplarını yazabilecekleri ikinci bir kısım olmak üzere yeniden düzenlenmiştir. Bu kapsamda ankette yer alan velilerin çocuklarının Bilim Fuarına hangi alanda katılmasını istediği yönündeki açık uçlu sorunun da seçeneklerin verildiği yapılandırılmış bölüm ve velilerin kendi cevaplarını yazabilecekleri bir kısımdan oluşması kararlaştırılmıştır.

Anket formlarının pilot çalışması TÜBİTAK 4006 Bilim Fuarlarına bir önceki sene fen projeleri ile katılan 11 öğrenci velisi ile yapılmıştır. Pilot çalışma sonrası anket formunda öğrenci velilerinin cevaplamakta zorlandığı ve istenilen düzeyde bilgi alınmayacağı anlaşılan TÜBİTAK 4006 Bilim Fuarlarının amaçları ve bu etkinliklerin daha etkili yapılabilmesi için velilerini görüşleri yönündeki 2 soru anketten çıkarılmıştır. Pilot çalışma sonrası son hali verilen anket formunun ve biri iki kısımdan oluşan 7 sorudan oluşmasına ve cevaplamaları için öğrenci velilerine 20-30 dk. süre 
verilmesine karar verilmiştir. Ankette yer alan 1. ve 6. soru maddesinde cevaplar açı uçlu iken, 2. 4. ve 7. soru maddeleri için cevaplar evet-hayır yönündedir. Evet, hayır yönündeki 4. ve 7. sorular için öğrenci velilerinden cevaplarının nedenlerini açıklamaları istenmiştir. Çalışmanın 3. ve 5. soru maddelerinde ise velilerin birden fazla seçeneği işaretlenebileceği yapılandırılmış bölümünün yanı sıra soru ile ilgili kendi cevaplarını yazabilecekleri ikinci bir kısım verilmiştir.

\section{Verilerin Analizi}

$\mathrm{Bu}$ araştırmada içerik analizinden yararlanılmıştır. İçerik analizinde temel amaç, toplanan verileri açiklayabilecek kavramlara ve ilişkilere ulaşmaktır. Bu analizde temelde yapılan işlem, birbirine benzeyen verileri belirli kavramlar ve temalar çerçevesinde bir araya getirmek ve bunları okuyucunun anlayabileceği bir biçimde organize ederek yorumlamaktır (Yıldırım \& Şimşek, 2011). Bu araştırmada elde edilen verilerin analizinde istatistiki işlemlerden olan yüzde ve frekanslardan yararlanılmıştır. Bunun dışında bazı sorularda velilerin soruya verdikleri cevaplar okuyucuya aynen sunulmuştur. Araştırmadan güvenirliğini sağlamak amacıyla elde edilen veriler analiz edilirken uzman görüşü alınmıştır. Çalışmadan elde edilen verilerin analizleri iki araştırmacı ile yapılmış elde edilen bulguların birbiri ile \%100 uyuştuğu görülmüştür. Çalışmada velilerinin anket sorularına verdiği cevapların analizinden elde edilen bulgular tablolarla okuyucuya sunulmuştur. Bazı soru maddelerinin analizinde öğrenci velilerinin soru ile ilgili verdiği cevaplar birden fazla kategoriye dâhil edilmiş, bu durum ilgili sorunun altında okuyucuya bildirilmiştir.

\section{Bulgular ve Yorum}

Bu bölümde TÜBİTAK 4006 Bilim Fuarlarına fen projeleri ile katılan 30 öğrencinin geliştirilen anket formunda yer alan 5 açık uçlu olmak üzere 7 soruya verdikleri cevapların analizlerinden elde edilen bulgulara yer verilmiş̧ir. Anketin birinci sorusu olan ve açık uçlu sorulan "Bilim fuarları denildiğinde aklınıza neler geliyor?" sorusuna verilen cevapların analizinden elde edilen bulgular Tablo 1'de verilmiştir.

Tablo 1.

Bilim Fuarları Denildiğinde Velilerin Akullarına Neler Geldiği Yönündeki Cevaplarınin Analizi

\begin{tabular}{lcc}
\hline & \multicolumn{2}{c}{$\mathrm{N}=30^{*}$} \\
Kodlar & (f) & $(\%)$ \\
\hline İcat yapmak & 17 & 56,6 \\
Deney yapmak & 13 & 43,3 \\
Proje yapmak & 8 & 26,6 \\
Yenilikler & 4 & 13,3 \\
Fikrim yok & 3 & 10 \\
\hline
\end{tabular}

* Bazı velilerin cevapları birden fazla kategoriye dâhil edilmiştir. 
Tablo 1 incelendiğinde; bilim fuarı denilince velilerin akıllarına gelen ilk ifadenin \%56,6 “icat yapmak” ifadesi olduğu görülmektedir. Bunu \%43,3 “deney yapmak” ve \%26,6 ile "Proje yapmak" ifadeleri izlemektedir. Soru ile ilgili en düşük oran sahip ifade ise \%13,3 ile "Yenilikler" ifadesidir. Çalışmaya katılan öğrenci velilerinin \%10'unun ise bu soruyu "fikrim yok” şeklinde cevapladığı görülmektedir.

Anketin ikinci sorusu olan ve cevabın evet hayır yönünde hazırlandığı "Daha önce bilim fuarını izlemeye geldiniz mi" sorusuna verilen cevapların analizinden elde edilen bulgular Tablo 2“de verilmiştir.

Tablo 2.

Velilerin Daha Önce Bilim Fuarını İzlemeye Gelme Durumuna Yönelik Cevaplarının Analizi

\begin{tabular}{lcc}
\hline Kodlar & & $\mathrm{N}=30$ \\
\hline Evet, daha önce bilim fuarlarını izlemeye geldim & 9 & $(\%)$ \\
Hayır, daha önce bilim fuarlarını izlemeye gelmedim & 21 & 26,6 \\
\hline
\end{tabular}

Tablo 2 incelendiğinde; öğrenci velilerinin daha önce bilim fuarı izlemeye gelip gelmediği yönündeki görüşlerini belirlemek amacıyla hazırlanan bu soruyu öğrenci velilerin \%26,6'sının "Evet daha önce bilim fuarlarını izlemeye geldim" yönünde cevaplarken \%73,4'ünün ise "Hayır daha önce bilim fuarlarını izlemeye gelmedim" şeklinde cevapladığı görülmektedir.

Anketin üçüncü sorusu olan "Çocuklarınızın Bilim Fuarına hangi alanda katılmasını istersiniz” sorusuna verilen cevapların analizinden elde edilen bulgular Tablo 3"de verilmiştir.

Tablo 3.

Velilerin Bilim Fuarına Çocuklarınızın Hangi Alanda Katılmasını İstediklerine Yönelik Cevaplarının Analizi

\begin{tabular}{lcc}
\hline & \multicolumn{2}{c}{$\mathrm{N}=30$} \\
Dersler & (f) & $(\%)$ \\
\hline Fen & 20 & 66,6 \\
Din Kültürü ve Ahlak Bilgisi & 11 & 36,6 \\
Türkçe & 5 & 16,6 \\
Matematik & 3 & 10 \\
İngilizce & 1 & 3,3 \\
Sosyal bilgiler & 1 & 3,3 \\
Diğer (Resim) & 1 & 3,3 \\
\hline
\end{tabular}

* Bazı velilerin cevapları birden fazla kategoriye dâhil edilmiştir. 
Tablo 3 incelendiğinde velilerin çocuklarının bilim fuarına \%66,6 ile fen projeleriyle, \%36,6 ile Din Kültürü ve Ahlak Bilgisi projeleriyle, \%16,6 ile Türkçe ve $\% 10$ matematik projeleriyle katılmasını istedikleri görülmektedir.

Anketin dördüncü sorusu velilerinin fen alanında hazırladığı projelerle Bilim Fuarına proje hazırlama sürecinde çocuklarına yardım edip etmedikleri yönündeki görüşlerinin alınmak istendiği "Proje hazırlama sürecinde çocuğunuza yardımcı oluyor musunuz? Oluyorsanız nasıl?" sorusuna verilen cevapların analizinden elde edilen bulgular Tablo 4'de verilmiştir.

Tablo 4.

Bilim Fuarına Proje Hazırlama Sürecinde Çocuğunuza Yardımcı Oluyor Musunuz?” Sorusuna Yönelik Veli Cevaplarının Analizi

\begin{tabular}{lcc}
\hline Kodlar & & $\mathrm{N}=30$ \\
\hline Evet, yardımc1 oluyorum & (f) & $(\%)$ \\
Hayır, yardımc olamıyorum & 22 & 73,3 \\
\hline
\end{tabular}

Tablo 4 incelendiğinde velilerin \%73,3'ünün proje hazırlama sürecinde çocuklarına yardımcı olduğu, \%26,7'sinin yardımcı olamadığı görülmektedir.

Aşağıda bu soruyu "evet yardımc1 oluyorum" şeklinde V3, V21, V26 ve V30 kodlu öğrenci velilerinin konu ile ilgili görüşleri aynen aktarılmıştır.

“Evet, yardımcı oluyorum. Proje için gerekli malzemeleri temin ediyorum.” (V3)

"Evet, yardımcı oluyorum. Projenin yapım aşamasında çocuğuma yardımcı oluyorum." (V30)

"Evet, yardımcı oluyorum projeyi nasıl daha iyi yapabiliriz diye çocuğumla fikir alışverişi yapıyoruz. Sonra da projeyi yapmayı başlıyoruz” (V21).

"Evet, yardımc oluyorum. Benim yapabileceğim bir şeyse yapımında yardım ediyorum. Bazen dışardan yardım almamı gerekiyor o aşamada da yardımcı oluyorum" (V26).

Çalışmada öğrenci velilerine sorulan beşinci soru öğrencilerinin bilim fuarına fen alanında projelerle katılmasının onlara sağlayacağı katkılara ilişkindir. Bu kapsamda soru iki kısma ayrılmıştır. İlk kısımda bu etkinliğe katılmanın öğrencilerin hangi özelliklerine katkı sağlayabileceği araştırılırken ikinci kısımda derslere olan katkıları araştırılmaya çalışılmıştır. Sorunun her iki kısmında da sorular birden fazla seçeneğin işaretlenebileceği yapılandırılmış birinci bölüm ve velilerinin kendi cevaplarını yazabilecekleri ikinci bölümden oluşmaktadır. Sorunun ilk kısmı "Öğrencilerin bilim fuarına fen alanında hazırlayacağı projeler ile aktif olarak katılması sizce onların hangi özelliklerinin gelişmesine katkl sağlar?” şeklindedir. Öğrenci verilerinin soruya verdikleri cevapların analizinden elde edilen bulgular Tablo 5'de verilmiştir. 
Tablo 5 .

Öğrencilerinin Bilim Fuarına Fen Projeleri ile Katılmasının Hangi Özelliklerine Katkı Sağlayacă̆ına Yönelik Veli Cevaplarının Analizi

\begin{tabular}{lcc}
\hline & \multicolumn{2}{c}{$\mathrm{N}=30^{*}$} \\
Öğrencilerin özelliklerine sağlayabileceği katkılar & (f) & (\%) \\
\hline Yaratıcı düşünme yeteneğini geliştirir & 22 & 73,3 \\
Projeyi sözlü ve yazılı sunum ile kendini ifade etme yeteneğini geliştirir. & 20 & 66,6 \\
Kendisine özgüven duymasını sağlar. & 17 & 56,6 \\
Araştırmacı özelliğini geliştirir. & 16 & 53,3 \\
Sabırlı olmayı öğrenir. & 13 & 43,3 \\
Bilimsel yöntemlerle problem çözmeyi öğrenir. & 12 & 40 \\
Eleştirel düşünme yeteneği gelişir. & 10 & 33,3 \\
Bilinçli birey olmasına katkı sağlar & 8 & 26,6 \\
Zaman yönetimi gelişir. & 3 & 10 \\
Tablo ve grafik hazırlarken matematik kullanmanın önemini anlar. & 3 & 10 \\
Liderlik özelliğini geliştirir & 2 & 6,6 \\
Diğerleri & 0 & 0 \\
\hline
\end{tabular}

* Bazı velilerin cevapları birden fazla kategoriye dâhil edilmiştir.

Tablo 5 incelendiğinde; velilere göre bilim fuarlarına fen projeleri ile katılmanın öğrencilere sağlayacağı katkıların ilk sırasında \%73,3 ile "Yaratıcı düşünme yeteneği geliştirir" ifadesi gelmektedir. Bunu \%66,6 ile "Projeyi sözlü ve yazılı sunum ile kendini ifade etme yeteneğini geliştirir", \%56,6 ile "Kendisine özgüven duymasını sağlar" ve \%53,3 ile "Araştırmacı özelliğini geliştirir" ifadelerinin izlediği görülmektedir.

Beşinci sorunun ikinci kısmı "Öğrencilerin bilim fuarına fen projeleri ile katılması sizce onların derslerine ne gibi katkılar sağlar" şeklindedir. Öğrenci velilerinin soruya verdikleri cevapların analizinden elde edilen bulgular Tablo 6'da verilmiştir.

Tablo 6.

Öğrencilerinin Bilim Fuarına Fen Projeleri ile Katılmasının Derslerine Sağlayacă̆ Katkılara İlişkin Veli Cevaplarının Analizi

\begin{tabular}{lcc}
\hline & \multicolumn{2}{c}{$\mathrm{N}=30^{*}$} \\
Derslere sağlayabileceği katkılar & (f) & $(\%)$ \\
\hline Fen dersine karşı ilgiyi artıır. & 21 & 70 \\
Fen dersini daha çok sevmesini sağlar. & 19 & 63,3 \\
Okulda öğretilmeyen fen konularıyla da ilgilenir. & 17 & 56,6 \\
Fen dersine karşı motivasyonunu (güdülenmesini) arttırır & 13 & 43,3 \\
Fen dersine karşı başarısını artırır & 11 & 36,6 \\
Güncel fen konularını takip eder & 5 & 16,6 \\
Öğretmenin sınıfta anlattığı konulardan daha fazlasını araştırmak ister. & 3 & 10 \\
Diğerleri & 0 & 0 \\
\hline
\end{tabular}


* Bazı velilerin cevapları birden fazla kategoriye dâhil edilmiştir.

Tablo 6 incelendiğinde; öğrenci velilerine göre bilim fuarlarının fen projeleri ile katılmanın öğrencilerin derslerine sağlayabileceği katkıların başında \%70 ile "Fen dersine karşı ilgiyi artırır" ifadesinin geldiği görülmektedir. Bunu \%63,3 ile "Fen dersini daha çok sevmesini sağlar", \%56,6 ile "Okulda ögretilmeyen fen konularlyla da ilgilenir", \%43,3 ile "Fen dersine karşı motivasyonunu arttırır", \%36,6 ile "Fen dersine karşı başarısını artırır” ifadeleri izlemektedir.

Anketin altıncı sorusu velilerin fen alanında Bilim Fuarlarına proje hazırlama sürecinde karşılaştıkları problemlerle ilgili olan “Velisi bulunduğunuz öğrencinin Fen alanında Bilim fuarlarına proje hazırlama sürecinde siz problemle karşılaşıyor musunuz? Karşılaştı̆̆ınız problemler nelerdir? sorusudur. Öğrenci verilerinin soruya verdikleri cevapların analizinden elde edilen bulgular Tablo 7'de okuyucuya sunulmuştur.

Tablo 7.

Bilim Fuarlarına Fen Alanında Proje Hazırlama Sürecinde Karşılaşılan Problemlere Yönelik Veli Cevaplarının Analizi

\begin{tabular}{llllll}
\hline Evet, problem yaşadım. & \multicolumn{3}{c}{ Hayır, problem yaşamadım. } \\
Kodlar & \multicolumn{2}{c}{$\mathrm{N}=28$} & Kodlar & \multicolumn{2}{c}{$\mathrm{N}=2$} \\
& (f) & $(\%)$ & & (f) & $(\%)$ \\
\hline Malzeme teminindeki güçlükler & 19 & 63,3 & Problem yaşamadım & 2 & 6,6 \\
Öğrencilerin derslerini aksatması & 7 & 23,4 & & & \\
Maddi olumsuzluklar. & 5 & 16,7 & & & \\
Sabır eksikliği & 3 & 10,0 & & & \\
$\begin{array}{l}\text { Projeyi teorikten uygulamaya } \\
\text { geçirirken yaşanılan sıkıntılar }\end{array}$ & 2 & 6,6 & & & \\
\hline
\end{tabular}

Tablo 7 incelendiğinde öğrenci velilerinin \%93,4'ünün proje hazırlama sürecinde problem yaşadığı, \%6,6'sının ise yaşamadığı belirlenmiştir. Velilerin proje hazırlama sürecinde yaşadığı problemlerin başında \%63,3 ile "Malzeme teminindeki güçlükler", \%23,4 ile "ögrencilerin derslerini aksatması", \%16,7 ile "maddi sıkıntılar" olduğu görülmektedir.

Anketin yedinci sorusu evet-hayır yönünde hazırlanan ve cevabın gerekçelerinin istendiği "Gelecek sene okulunuzda bilim fuar yapılacak olsa çocuğunuzun fen alanında proje hazırlayarak fuara tekrar katılmasını ister misiniz? Niçin? şeklindedir. Öğrenci velilerinin soruya verdikleri cevapların analizinden elde edilen bulgular Tablo 8'de verilmiştir.

Tablo 8.

Seneye Çocuklarının Fen Projeleri ile Bilim Fuarına Tekrar Katılmasını İsteyip Istememe Yönündeki Veli Cevaplarının Analizi 


\begin{tabular}{|c|c|c|}
\hline \multirow[b]{2}{*}{ Kodlar } & \multicolumn{2}{|c|}{$\mathrm{N}=30$} \\
\hline & (f) & $(\%)$ \\
\hline Evet, kat1lmasın 1 isterim & 25 & 83,3 \\
\hline Hayır, katılmasını istemem & 5 & 16,7 \\
\hline
\end{tabular}

Tablo 8 incelendiğinde velilerin \%83,3'ünün çocuklarının bilim fuarına fen alanındaki projelerle tekrar katılmasını istedikleri, \%16,7'sinin ise katılmasını istemedikleri görülmektedir.

Aşağıda bu soruya "Evet, katılmasını isterim" şeklinde cevaplayan V9, V16 ve V27 kodlu öğrenci velilerinin görüşleri aynen aktarılmıştır.

“Evet, katılmasını isterim. Çünkü derslere olan ilgisi artıyor, meraklı oluyor, özellikle fen dersine (V9)"

"Evet, katılmasını isterim. Çünkü kendine olan özgüveni arttırıyor ve fen konularını daha çok seviyor (V16)"

"Evet, katılmasını isterim. Kendisini geliştirmesi sosyal olarak aktifleşmesi kendisini iyi ifade edebilmesi için (V27)"

Soruyu "Hayır katılmasını istemem" şeklinde cevaplayan beş öğrenci velisinden V11, V24 ve V25'in görüşleri aşağıda aynen verilmiştir.

"Hayır, katılmasını istemem, derslerine zaman ayıramıyor (V24, V25)"

"Hayır, katılmasını istemem çok zamanımızı alıyor. Bu yüzden sınavlarına çalışamıyor(V11)”

\section{Tartışma, Sonuç ve Öneriler}

TÜBİTAK 4006 Bilim Fuarlarına fen projeleri ile katılan öğrenci velilerinin bilim fuarları hakkındaki görüşlerinin belirlenmesi amacıyla yürütülen bu çalışmada "Bilim Fuarı" denilince velilerin aklına gelen ilk ifadenin \%56,6 "Ícat yapmak" olduğu Tablo 1'de görülmektedir. Bunu \%43,3 ile "Deney yapmak", \%26,6 ile "Proje yapmak" \%13,3 ile "Yenilikler” ifadeleri izlemektedir. TÜBİTAK Bilim Fuarları ile öğrencilerden; bireysel ilgileri doğrultusunda seçtikleri konuları inceleyerek projeler hazırlamaları, bilimsel araştırma süreçlerini yaşayarak öğrenmeleri, deney yapma disiplini kazanmalarının yanı sıra bu deneyler sırasında elde ettikleri bulguları ve araştırmalarının sonuçlarını sunumlar yaparak ifade etmeleri beklenmektedir (TÜBİTAK, 2018a). Dolayısıyla çalışmada bilim fuarları ifadesine dair velilerden elde edilen bulguların TÜBİTAK'ın belirttiği bilim fuarları ifadesine paralel olduğu söylenebilir. Literatürde Bilim fuarları hakkında öğrenci velilerinin görüşlerini belirlemeye yönelik bir çalışmaya rastlanmamıştır. Kılıç ve Özel (2015) tarafından velilerin proje çalışmalarına yönelik görüşlerini belirlemek amacıyla yürütülen bir çalışmada velilerin \%34,7'sinin proje çalışmalarını “ Ö̆̆rencilerin becerilerini artırmak için yapılan çalışmalar" olarak gördüğü ve bu sürecin öğrencilerin yeni bir 
ürün tasarlamak veya üretmesine yardımcı olduğunu belirttikleri vurgulanmıştır. $\mathrm{Bu}$ noktadan hareketle çalışmadan elde edilen sonucun literatürle örtüştüğü söylenebilir. Çalışmadan bu soru ile ilgili elde edilen bir diğer önemli bulgu öğrenci velilerinin \%10'unun bilim fuarları denilince aklınıza ne geliyor sorusunu "fikrim yok" şeklinde cevaplamış olmasıdır. Bu bulgu öğrencileri bu fuarlara katılan her 10 veliden birinin okullarda düzenlenen bilim fuarlarına amaçları hakkında fikir sahibi olmadıklarını göstermektedir. $\mathrm{Bu}$ çalışmada velilerin TÜBİTAK'ın hazırladığı veli kılavuz kitapçıklarını inceleyip incelenmediğini doğrudan sorgulanmasa da elde edilen bulgular bu kitapçıkların çocukları bilim fuarına katılan öğrenci velilerinin bir bölümü tarafından yeterince incelenmediğine işaret edebilir. Benzer duruma Kılıç ve Özel (2015) tarafından çalışmada da rastlanmış benzer soruyu çalışmaya katılan velilerin \%8,7'sinin soruyu "Yorumsuz" olarak cevapladığı belirtilmiştir. Dolayısıyla çalışmadan elde edilen bu yöndeki sonuçların literatürle desteklenmektedir.

Çalışmada öğrenci velilerinin çocuklarının bilim fuarına $\% 66,6$ ile fen projeleriyle katılmalarını istedikleri ve \%73,3'ünün proje hazırlama sürecinde onlara yardımc1 olduğu Tablo 3 ve 4'ten görülmektedir. Fakat çalışmada çocukları fen projeleri ile bilim fuarına katılan öğrenci velilerinin \%73,4'ünün daha önce bilim fuarını izlemeye gelmediği belirlenmiştir. Bu bulgu öğrenci velilerinin bilim fuarlarına yeterince önem vermediği şeklinde yorumlanabilir. Erdoğan ve Demirkasımoğlu (2010) tarafından öğretmen ve yönetici görüşleri alınarak yapılan bir çalışmada öğrenci velilerinin eğitim sürecine katılımın gerekli ve önemli görüldüğ̈̈; ancak çoğu velinin uygulamada hassasiyet gösteremediği rapor edilmiştir. Çolakoğlu (2018) tarafindan yapılan başka bir çalışmada ise velilerin bilim fuarlarına katılımcılarının az olduğu ve arttırılması gerekliliği vurgulanmıştır.

Fen projeleri ile bilim fuarlarına katılmanın öğrencilerin özeliklerine sağlayabileceği katkılara ilişkin çalışmadan elde edilen veli görüşleri incelendiğinde; ilk sırada \%73,3 “Yaratıcı düşünme yeteneğini geliştirir” ifadesinin geldiği Tablo 5 'de görülmektedir. Bunu \%66,6 ile "Projeyi sözlü ve yazılı sunum ile kendini ifade etme yeteneğini geliştirir" ve \%56,6 ile “Kendisine özgüven duymasını sağlar” ifadeleri izlemektedir. Literatürde velilerin bilim fuarları hakkında görüşlerini yansıtan bir çalışmaya rastlanamamasına rağmen proje çalışmaları ile ilgili öğrenci ve öğretmenlerle yapılan çalışmalarda, proje çalışmalarının öğrencilerin yaratıcılık yönlerinin gelişmesine katkılar sağlayabileceği bildirilmiştir (Avcı vd., 2016; Tonbuloğlu vd., 2013;). Bilim fuarlarının etkililiğinin değerlendirmek üzere Bozdemir (2018) ve Balcı (2019) tarafından yapılan çalışmalarda ise bu uygulamaların öğrencilerin özgüveninin artırdığı ve kendini ifade etme yeteneğini geliştirdiği belirtilmektedir.

Bilim Fuarlarına fen projeleri ile katılmanın öğrencilerin derslerine sağlayacağı katkılara ilişkin velilerden elde edilen görüşlerin ilk sırasında \%70 ile "Fen dersine karşı ilgiyi artırır" ifadesi gelmektedir. Bunu \%63,3 ile "Fen dersini daha çok sevmesini sağlar", \%56,6 ile "Okulda öğretilmeyen fen konularlyla da ilgilenir", 
\%43,3 ile "Fen dersine karşı motivasyonunu arttırı", \%36,6 ile "Fen dersine karşı başarısını artırır" ifadeleri takip etmektedir. Bu bulgulardan velilerinin Bilim Fuarlarına fen projeleri ile katılmanın öğrencilerin fen dersine karşı tutum ve motivasyon geliştirilmesinin yanı sıra fen dersi başarılarının artırılmasına katkılar sağlayabileceği görüşüne sahip olduğu sonucuna ulaşılabilir. Bilim Fuarlarına fen projeleri ile katılmanın öğrencilerin derslerine sağlayacağı katkılara ilişkin veli görüşlerini yansıtan bir çalışmaya literatürde ulaşılamamıştır. Fakat Bilim Fuarları ile ilgili öğretmen ve öğrenci görüşlerini yansıtan çalışmalardan elde edilen sonuçların bu çalışmadan elde edilen sonuçları destekler nitelikte olduğu belirlenmiştir (Kaya \& Böyük, 2011; Mupezeni \& Kriek, 2018; Şahin, 2012; Bozdemir, 2018; Balc1, 2019).

Çalışmada Bilim Fuarına fen projeleri ile katılan 30 öğrenci velisinden 28'inin bu süreçte problemler yaşadığı belirlenmiştir. Velilerin yaşadığı problemlerin \%63,3 ile "Malzeme teminindeki güçlükler", \%23,4 ile "Öğrencilerin derslerini aksatması", \%16,7 ile "Maddi stkintılar", \%10 "Sabır eksikliği" ve \%6,6 "Projeyi teorikten uygulamaya geçirirken yaşanılan sıkıntılar" olduğu görülmektedir. Bu bulgulardan özellikle "Malzeme teminindeki güçlükler", "Sabır eksikliği", "Projeyi teorikten uygulamaya geçirirken yaşanılan sıkıntılar" dikkat çekicidir. Bu bulgular velilerin, çocuklarının proje ödevlerini üstlendiğinin işareti olabilir. Çalışmanın dördüncü sorusu olan "Bilim fuarına proje hazırlama sürecinde çocuğunuza yardımcı oluyor musunuz?" sorusundan elde edilen bulguların da bu sonucu desteklediği söylenebilir. Soruya ilişkin proje hazırlama sürecinde velilerin $\% 73,3$ 'ünün çocuklarına yardımcı olduğu belirlenirken velilerden elde edilen; "Projenin yapım aşamasında çocuğuma yardımcı oluyorum (V30)", "Projeyi nasıl daha iyi yapabiliriz diye çocuğumla fikir alışverişi yapıyoruz. Sonra da projeyi yapmayı başllyoruz (V21)", Benim yapabileceğim bir şeyse yapımında yardım ediyorum. Bazen dışardan yardım almamı gerekiyor o aşamada da yardımcı oluyorum (V26)" yönündeki görüşler, velilerin öğrencilerin proje ödevlerini üstlendiği sonucunu güçlendirmektedir. Bilim Fuarlarını temelini oluşturan proje temelli öğrenme sürecinde ailelere önemli roller düşmesine rağmen (Kılıç \& Özel, 2015), projelerin öğrenciler yerine öğrenci velileri tarafından üstlenilmesi önemli bir sonuçtur. Bu sonuç Stern and Huber (1997), Ersoy ve Anagün (2009), Öztuna Kaplan ve Diker Coşkun (2012) tarafından yapılan çalışmalardan elde edilen; proje çalışmalarına velilerin gereğinden fazla dâhil olduğu, velilerin öğrencinin rolünü üstlendiği, velilerin öğrencinin hazırladığı proje ile ne öğrendiğinden ziyade iyi not almaları ile ilgilendikleri, yönündeki sonuçlarla benzerlik göstermektedir. Kılıç ve Özel (2015) tarafindan yapılan bir çalışmada; velilerin \%22'si okullarda verilen proje çalışmalarını aileler tarafından yapıldığı için faydalı görmedikleri rapor edilmiştir. Bu soru ile ilgili elde edilen bir diğer önemli bulgu ise velilerin \%23,4'ünün Bilim Fuarlarını öğrencilerin dersleri aksatan bir uygulama olarak görmesidir. Bu nokta Proje Tabanlı Öğrenme ile ilgili Özel (2013) tarafından yapılan çalışmada da vurgulanmış, öğretmenlerin proje çalışmalarının müfredatın sağlıklı işlemesinde sıkıntılara neden olduğu belirtilmiştir. Güncellenen 2018 Fen Bilimleri Dersi Öğretim Programına bakıldığında ise bu noktada adımlar atıldı̆̆ı, öğrencilerin yıl içerisinde ortaya çıkardıkları ürünleri Bilim fuarları 
şenliklerinde etkili bir şekilde sunmaları için 4.sınıfta 9 ve diğer sınıflarda ise 12 ders saati olmak üzere ayrı bir zaman ayrıldığı görülmektedir (MEB, 2018).

Araştırmada velilerinin \%83,3'ünün öğrencilerinin fen alanında projeler hazırlayarak seneye tekrar Bilim Fuarına katılmasını istediği belirlenmiştir. Buna neden olarak ise Bilim Fuarlarına katılmanın onların fen dersine olan ilgi ve merakının artmasına, dersi daha çok sevmesine ve kendine olan özgüvenin artması ve sosyalleşmesine yardımcı olması gösterilmektedir. Çalışmaya katılan öğrenci velilerinin \% 16,7'sinin ise" zaman kaybi", "derslere zaman ayıramama”, "sinavlara çalışamama" gibi nedenlerle öğrencilerinin tekrar Bilim Fuarlarına katılmasını istemedikleri belirlenmiştir. Elde edilen bu yöndeki bulgular bazı öğrenci velilerinin çocuklarının Bilim Fuarlarının katılmasının onlara sağlayabileceği yararlara inanmadığı şeklinde yorumlanabilir. Bu bulgu ayrıca yukarıda değinilen Bilim Fuarları veli kılavuz kitapçıklarının veliler tarafından yeterince incelenmediği sonucunu desteklediği gibi kılavuz kitaplarının yeterince etkili olmadığ sonucuna da işaret etmektedir. Oysa Bilim Fuarları bu etkinliklere katılan öğrencileri pek çok açıdan geliştirdiği gibi etkili fen eğitimi noktasında oldukça önemlidir (Çavuş vd., 2018; Sontay vd., 2019). Dolayısıyla okullarda düzenlenen Bilim Fuarlarının amaçlarına ulaşması noktasında öğrenci velilerinin bu uygulama ile ilgili olumsuz düşüncelerinin giderilmesi gerekmektedir.

Bu çalışma TÜBİTAK 4006 Bilim Fuarlarına fen projeleri ile katılan öğrenci velilerinin Bilim Fuarları hakkındaki görüşlerini belirlemek amacıyla yürütülmüştür. Çalışmada velilerin tamamına yakınının; öğrencilerin Bilim Fuarlarına fen projeleri ile katılmasının onların yaratıcılık başta olmak üzere öğrencilerin farklı özelliklerinin gelişmesine katkı sağladığı görüşünde olduğu belirlenmiştir. Çalışmada ayrıca velilerin bu etkinliklere katılmanın, öğrencilerin fen dersine yönelik başarı, tutum ve motivasyonun attırılmasına yardımcı olduğu görüşüne sahip olduğu da saptanmıştır. TÜBİTAK tarafından Bilim Fuarları düzenlenen okullar desteklenmesine rağmen bu uygulamaların daha çok okulda, daha etkili olarak düzenlenmesi için görev alan öğretmenlere sağlanacak ek bir ücretin, onların çalışma azmini ve motivasyonunu artırabileceği düşünülmektedir. Çalışmadan elde edilen bir diğer önemli sonuç ise 4006 TÜBITTAK Bilim Fuarları veli kılavuz kitapçığı olmasına rağmen öğrencileri fen alanında projelerle araştırmaya katılan öğrenci velilerinin \%10'unun TÜBİTAK 4006 Bilim Fuarları ile ilgili herhangi bir fikri olmadığıdır. Konu ile ilgili velilere verilecek bir eğitimin onların bu etkinliklerdeki rollerinin belirlenmesinde yardımcı olacağı gibi konuya yaklaşımlarını önemli ölçüde etkileyebilir. Çalışmada bazı öğrenci velilerinin Bilim Fuarları için öğrencilerin hazırlaması gereken projeleri üstlendiğine işaret eden bulgulara rastlanırken bazı velilerin de öğrencilerinin Bilim Fuarlarına tekrar katılmasını istemediği belirlenmiştir. Bu kapsamda veli kılavuz kitaplarının; Bilim Fuarlarının öğrenciler için önemi ve öğrencilerin bu etkinliklerden maksimum düzeyde katkılar sağlayabilmesi noktasında velilere düşen görevler konuları başta olmak üzere yeniden düzenlemesi uygulamanın amaçlarına ulaşmasına önemli katkılar sağlayabilir. 


\section{Çıkar Çatışması ve Etik Bildirimi}

$\mathrm{Bu}$ çalışma araştırma ve yayın etiği kurallarına uyularak ve gerekli izinler alınarak yapılmıştır. Çalışma, araştırma ve yayın etiği kuralları gereği; Ağrı İl Milli Eğitim Müdürlügü, 20/07/2016 tarih ve 34550427/300/7709481 nolu olur yazısı kapsamında yürütülmüştür.

\section{Kaynakça}

Akbaba Altun, S. (2009). İlköğretim öğrencilerinin akademik başarısızlıklarına ilişkin veli, öğretmen ve öğrenci görüşlerinin incelenmesi. İlköğretim Online, 8(2), 567-586.

Avc1, E., \& Su Özenir, Ö. (2018). Bilim fuarları sürecinin yürütücü öğretmenler gözünden değerlendirilmesi, $\quad$ Ilköğretim $\quad$ Online, $\quad 17(3), \quad$ 1672-1690. https://doi.org/10.17051/ilkonline.2018.466417

Avc1, E., Su Özenir, Ö., \& Yücel, E. (2016). TÜBİTAK ortaöğretim öğrencileri araştırma projeleri yarışmasına katılan öğrencilerin yarışma sonrası kazanımlarının incelenmesi. Uşak Üniversitesi Sosyal Bilimler Dergisi, 9(27/3), 1-21.

Balc1, E. (2019). TÜBİTAK 4006 Bilim fuarlarının değerlendirilmesi: Polatlı örneği (Tez No. 538149) [Yüksek lisans tezi, Bolu Abant İzzet Baysal Üniversitesi- Bolu]. Yükseköğretim Kurulu Başkanlığı Tez Merkezi.

Bahar, M., Nartgün, Z., Durmuş, S., \& Bıçak, B. (2014). Geleneksel-tamamlayıcı ölçme ve değerlendirme teknikleri ögretmen el kitabı. Pegem Akademi.

Bolat, A., Bacanak, A., Kaşıkçı, Y., \& Değirmenci, S. (2014). Bu benim eserim proje çalışması hakkında öğretmen ve öğrenci görüşleri. Eğitim ve Öğretim Araştırmaları Dergisi, 3(4), 100-110.

Bozdemir, E. (2018). TUBİTAK bilim fuarlarında yapılan projelerin öğrenciler üzerindeki etkililiğinin değerlendirilmesi (Tez No. 495549) [Yüksek lisans tezi, Çanakkale Onsekiz Mart Üniversitesi- Çanakkale]. Yükseköğretim Kurulu Başkanlığı Tez Merkezi.

Cohen, L., Manion, L., \& Morrison, K. (2000). Research methods in education. Routledge Falmer.

Çavuş, R., Balçın, M. D., \& Yılmaz, M. (2018). Bilim fuarı etkinliklerinin ortaokul öğrencilerinin fen ve problem çözme becerilerine yönelik algılarına etkisi, İnönü Üniversitesi Eğitim Bilimleri Enstitüsü Dergisi, 5(10),1-17. https://doi.org/10.29129/inujgse.395132

Çepni, S. (2012). Araştırma ve proje çalışmalarına giriş̧ (Geliştirilmiş 6. Baskı). Celepler Matbaacilik.

Çepni S., Ayvacı H., Ş., \& Bakırcı, H. (2012). Veli rehber materyalinin yapılandırmacı yaklaşım içinde fen ve teknoloji öğretimine etkileri üzerine bir ön çalışma, Millî Eğitim Dergisi, 195, 134-145. 
Çolakoğlu, M. H. (2018). TÜBİTAK 4006 bilim fuarları desteğinin eğitim ve öğretime katkısı. Bilim, Teknoloji, Mühendislik, Matematik ve Sanat Eğitimi Dergisi, 1(1), 48-63. https://dergipark.org.tr/tr/download/article-file/488392

Demiral, Ü. (2015). Proje tabanlı öğrenme yaklaşımı. G. Ekici (Ed.) Etkinlik örnekleriyle güncel öğrenme-ögretme yaklaşımları-II içinde (s. 459-500). Pegem Akademi Yayıncılık.

Demiray, P. (2013). Proje tabanlı öğrenme modelinin etkililiği: Bir meta analiz çalışması. (Tez No. 347368) [Yüksek lisans tezi, Ankara Üniversitesi-Ankara]. Yükseköğretim Kurulu Başkanlığı Tez Merkezi.

Dilşeker, Z. (2008). Fen ve teknoloji dersinde proje tabanlı ögrenme yöntemi kullanımının ilköğretim 5. sinıf ögrencilerinin fen ve teknoloji dersine yönelik tutumlarına, ders başarısına ve kavram yanılgılarının giderilmesine etkisi (Tez No. 230948) [Yüksek lisans tezi, Dokuz Eylül Üniversitesi-İzmir]. Yükseköğretim Kurulu Başkanlığı Tez Merkezi.

Doğay, G. (2010). Ekoloji ünitesinin öğrenilmesinde proje tabanlı öğrenme yönteminin öğrenci başarısına etkisi (Tez No. 278285) (Yüksek lisans tezi, Gazi Üniversitesi-Ankara]. Yükseköğretim Kurulu Başkanlığı Tez Merkezi.

Efe, R., \& Aslan Efe, H. (2018). Science student teachers' approaches to studying, International Journal of Educational Studies (IEJES), 2 (3), 53-63. https://doi.org/10.31458/iejes.376848

Erdoğan, Ç., \& Demirkasımoğlu, N. (2010). Ailelerin eğitim sürecine katılımına ilişkin öğretmen ve yönetici görüşleri. Kuram ve Uygulamada Eğitim Yönetimi, 16(3), 399-431.

Ersoy, A., \& Anagün, S., Ş. (2009). Sınıf öğretmenlerinin fen ve teknoloji dersi ödev sürecine ilişkin görüşleri, Necatibey Ĕğitim Fakültesi Elektronik Fen ve Matematik Ĕgitimi Dergisi (EFMED), 3(1), 58- 79.

Grix, J. (2010). The foundations of research. Palgrave Mac llan.

Güvey, E. (2009). İlköğretim 1-5. sinıf öğretim programlarında yer alan proje ve performans görevlerine ilişkin ögretmen ve veli görüşleri (Eskişehir ili örneği) (Tez No. 239409) [Yüksek lisans tezi, Eskişehir Osmangazi Üniversitesi-Eskişehir]. Yükseköğretim Kurulu Başkanlığı Tez Merkezi.

Kaşarc1, İ. (2013). Proje tabanl öğrenme yaklaşımının öğrencilerin akademik başarı ve tutumlarına etkisi: Bir meta-analiz çalışması, (Tez No. 322081) [Yüksek lisans tezi, Eskişehir Osmangazi Üniversitesi-Eskişehir]. Yükseköğretim Kurulu Başkanlığı Tez Merkezi.

Kavacık, İ., Kılınç, H., \& Kavacık, L. (2015, Nisan, 16-19). Ortaokul fen bilimleri ögretmenlerinin bu benim eserim proje yarışmasına proje hazırlama süreci ile ilgili görüşlerinin bazı değişkenlere göre incelenmesi. 24. Ulusal Eğitim Bilimleri Kongresi, Niğde. 
Kaya, H., \& Böyük, U. (2011). İlköğretim II. kademe öğrencilerinin fen ve teknoloji dersine ve fen deneylerine karşı tutumları. Tübav Bilim Dergisi, 4(2), 120-130.

Kılıç, İ., \& Özel, M. (2015). Proje tabanlı öğrenme yönteminin fen ve teknoloji derslerinde uygulamaları hakkında öğretmen ve veli görüşlerinin incelenmesi. Sakarya University Journal of Education, 5(2), 7-20. https:// dergipark.org. tr/tr/pub/ suje/issue/20639

MEB (2017, Mayıs). Temel eğitim genel müdürlüğ̈̈ fen bilimleri dersi öğretim programı tanıtımı, ögretim programı tanıtım sunusu, Güncellenen öğretim programlarının eğitici eğitimi, 3-26 Mayıs 2017, Antalya Aydın. http://tegm.meb.gov.tr/meb_iys_dosyalar/2017 06/09163104 Fen Bilimleri Dersi Öğretim Programın Karşılaştırmaları.

MEB (2018). Illkögretim kurumlan (ilkokullar ve ortaokullar) fen bilimleri dersi (3, 4, 5, 6, 7 ve 8. sinıflar) ögretim programı. Ankara, Talim Terbiye Kurulu Başkanlığ http://mufredat.meb.gov.tr/

Mupezeni, S., \& Kriek, J. (2018). Out of school activity: A comparison of the experiences of rural and urban participants in science fairs in Limpopo Province, South Africa. EURASIA Journal of Mathematics, Science and Technology Education, 14(8), 1-12.

Özel, M. (2013). Proje tabanlı öğrenme yönteminin İlköğretim 2. kademe Fen ve Teknoloji derslerindeki uygulanmasının incelenmesi (Tez No. 346479) (Yüksek lisans tezi, Trakya Üniversitesi Fen Bilimleri Enstitüsü-Edirne]. Yükseköğretim Kurulu Başkanlığı Tez Merkezi.

Öztuna Kaplan, A., \& Diker Coşkun, Y. (2012). Proje Tabanlı Öğretim Uygulamalarında Karşılaşılan Güçlükler ve Çözüm Önerilerine Yönelik Bir Eylem Araştırması. Mersin Üniversitesi Ĕ̌itim Fakültesi Dergisi, 8(1), 137-159.

Özünal, S. (2016). Ortaokullarda coğrafya konularının öğretiminde proje tabanlı öğrenmenin öğrenci başarısına etkisi. International Periodical for the Languages, Literature and History of Turkish or Turkic, 11(3), 1903-1918. https://doi.org/10.7827/TurkishStudies.9126

Solomon, G. (2003). Project-based learning: A primer. Technology and Learning, 23(6), 2030.

Sontay, G., Anar, F., \& Karamustafaoğlu, O. (2019). TÜBİTAK 4006 bilim fuarına katılan ortaokul öğrencilerinin bilim fuarı hakkındaki görüşleri, International e-Journal of Educational Studies,3 (5) ,16-28. https://doi.org/10.31458/iejes.423600

Stern, D., \& Huber, G. L. (Eds.) (1997). Active learning for students and teachers: reports from eight countries. Peter Lang.

Şahin, Ş. (2012). Bilim şenliklerinin 10. sınıf öğrencilerinin kimya dersine yönelik tutumlarına olan etkisi. Uşak Üniversitesi Sosyal Bilimler Dergisi, 5(1), 89-103.

Taymaz, H. (2001). Okul yönetimi. Pegem A Yayınc1lık. 
Thomas, R. M. (1998). Conducting educational research: A comparative view. Bergin \& Garvey.

Tonbuloğlu, B. Aslan, D. Altun, S., \& Aydın, H. (2013). Proje tabanlı öğrenmenin öğrencilerin biliüstü becerileri ve öz-yeterlilik algıları ile proje ürünleri üzerindeki etkisi. Mustafa Kemal Üniversitesi Sosyal Bilimler Enstitüsü Dergisi, 10(23), 97-117.

TÜBİTAK. (2018a) Öğretmenler için 4006-TÜBİTAK bilim fuarları kılavuzu, TÜBİTAK Bilim ve Toplum Daire Başkanlığı, Bilim ve Toplum Programları Müdürlüğü, Bakanlıklar/Ankara.

https://www.tubitak.gov.tr/sites/default/files/2204/ogretmenler_icin_4006 tubitak.

TÜBİTAK. (2018b). 4006 TÜBİTAK bilim fuarları destekleme programı http://www.tubitak.gov.tr/tr/destekler/bilim ve-toplum/ulusal-destek-programlari/icerik$\underline{4006}$.

TÜBİTAK. (2018c) Öğrenciler için 4006-TÜBİTAK bilim fuarları kılavuzu, TÜBİTAK Bilim ve Toplum Daire Başkanlığı, Bilim ve Toplum Programları Müdürlüğü, Bakanlıklar/Ankara. https://www.tubitak.gov.tr/sites/default/f2204/ogrenciler_icin_4006$\underline{\text { tubitak_bilim_fuar }}$

TÜBİTAK. (2018d). Okul müdürleri için 4006-tübitak bilim fuarları kılavuzu, TÜBITAK bilim fuarları kılavuzu, TÜBITAK Bilim ve Toplum Daire Başkanlığı, Bilim Ve Toplum Programları Müdürlügüu, Bakanlıklar/Ankara. https:// www.tubitak.gov.tr/ sites/default/files /2204/okul_mudurleri_icin_4006-tubitak_bilim

Yaşar, Ş. (2010). Yapılandırmacı yaklaşımda öğretmenin, öğrencinin ve velinin rolü “EğitimBirSen Dergisi, 17, 15-19.

Yıldırım, A. \& Şimşek, H. (2011). Sosyal bilimlerde nitel araştırma yöntemleri (8. Bask1). Seçkin Yayıncılık.

Yılmaz, F. N. (2015). Fen bilimleri öğretiminde proje tabanlı öğrenme yaklaşımının 6. sınıf ögrenci başarısı ve bilimsel süreç becerilerine etkisi (Tez No. 407000) (Yüksek lisans tezi, Pamukkale Üniversitesi-Denizli]. Yükseköğretim Kurulu Başkanlığı Tez Merkezi.

\section{Extended Abstract}

One program that allows students to actively take part in the projects is "Scientific and Technological Research Council of Turkey (TÜBİTAK) 4006 Science Fairs." In Science Fairs, it is stated that students can learn scientific research processes through sub-projects prepared in line with their individual interests, as well as develop critical thinking, time management, problem solving, self-confidence and leadership qualities (TÜBİTAK, 2018a). Although there are studies in the literature that reflect the views of the teachers-students about Science Fairs, there is no study reflecting the opinions of the parents of students who participated in science fairs with science projects about 
this practice. This study was carried out to determine the opinions of the parents of students who participated in TÜBITTAK 4006 Science Fairs with science projects about science fairs.

Case studies method was used in the research. The sample of the study consists of 30 parents whose children participated in TÜBİTAK 4006 Science Fairs with science projects and who attended to watch these activities. Seven question questionnaire form consisting of different question types, developed by researchers, was used as data collection tool.

In this study carried out to determine the views of the parents of students who participated in TÜBITAK 4006 Science Fairs with science projects about science fairs, it is seen that the first expression that came to the minds of parents is to invent $(56.6 \%)$ when it comes to the "Science Fair." This was followed by "Experimenting" (43.3\%), "Doing a Project" (26.6\%) and "Innovations" (13.3\%). With TÜBİTAK Science Fairs, students are expected to examine the topics they have chosen in line with their individual interests, to prepare projects, to learn through scientific research processes, to gain discipline to conduct experiments and to express their findings and the results of their research by making presentations (TÜBITAK, 2018a). Therefore, it can be said that the findings obtained from parents regarding the expression of science fairs in the study are parallel to the expression of science fairs stated by TÜBİTAK. In the study, it was determined that $66.6 \%$ of the parents wanted their children to participate in science fairs with science projects and $73.3 \%$ of them helped them in the project preparation. However, in the study, it was determined that $73.4 \%$ of the parents whose children participated in the science fair with science projects didn't attend to follow the science fairs before. This finding can be interpreted that the parents don't pay enough attention to science fairs. In a study conducted by Erdoğan and Demirkasımoğlu (2010) on the opinions of teachers and administrators, it was reported that participation of parents in the education process was considered necessary and important, but most parents were not sensitive in practice. When the parents' views on the contributions of science projects and science fairs to the characteristics of the students were examined, it was determined that "Improves creative thinking ability" (73.3\%) takes the first place. This is followed by the statements like "Improves the ability to express themselves through oral and written project presentation" (66.6\%) and "Provides self-confidence" (56.6\%). It was reported in the literature that project studies will contribute to the development of students' creativity, increase their self-confidence and improve their ability to express themselves (Avc1, Özenir \& Yücel, 2016; Bozdemir 2018). When the views of parents regarding the contributions of science fairs to students' participation in science fairs are examined, the expression "increases interest in science lesson" comes first (70\%). This is followed by the expressions like "Makes them love Science lessons more" $(63.3 \%)$, "They are interested in science subjects not taught in the school" (56.6\%), "Increases their motivation towards Science lessons" (43.3\%) and "Increases their success in science lessons" (36.6\%). It can be concluded that parents think 
participating in Science Fairs with science projects may contribute to improving students' science lesson achievements and developing attitudes and motivations towards science lessons. No study that reflects parents 'views on the contributions of science fairs to students' classes was not reached in the literature. However, the results obtained from the studies that reflect the opinions of teachers and students about Science Fairs was determined to support the results obtained from this study (Bozdemir, 2018; Balc1, 2019). In this study, it was determined that 28 of 30 student parents experienced problems in this process. These are "Difficulties in material supply" (63.3\%), "Students' skipping classes" (23.4\%), "Financial difficulties" $(16.7 \%)$, "Lack of patience" (10\%) and "Problems in putting the project from theory to practice" $(6.6 \%)$. These findings may be a sign that parents undertake students' project assignments. It was determined that the findings obtained from the fourth question "Do you help your child during the project preparation process for Science Fair?", which is the fourth question of the study, support this result. Although there are important roles for families in the project-based learning process that forms the basis of Science Fairs, it is an important result that projects are undertaken by parents rather than students. This result is similar to the results obtained from the study of Öztuna Kaplan and Diker Coşkun (2012) that parents undertake the student's role in the project studies. In the study, it was determined that $83.3 \%$ of the parents wanted their children to participate in the Science Fair by preparing projects in the field of science. The reason for this is that participating in Science Fairs helps them increase their interest and curiosity towards science lesson, love the lesson more and increase their self-confidence and socialize. It was determined that $16.7 \%$ of the parents did not want their children to attend Science Fairs due to reasons such as "loss of time", "not being able to spare time for classes" and "not being able to study for exams." Findings in this direction may indicate the conclusion that some parents do not believe in the benefits of Science Fairs or may indicate that the parent guidebooks prepared for Science Fairs are not sufficiently examined or that these booklets are not effective at the desired level. 